\title{
Catalytic Asymmetric Synthesis of CPZEN-45
}

Toshifumi Takeuchi, Hikaru Abe, Takumi Watanabe*, Masakatsu Shibasaki*

Institute of Microbial Chemistry (BIKAKEN),

Tokyo, 3-14-23 Kamiosaki, Shinagawa-ku, Tokyo 141-0021, Japan

\section{ABSTRACT:}

A catalytic asymmetric total synthesis of CPZEN-45 (1), anti-XDR-TB agent, was accomplished using a direct aldol reaction of a glycine Schiff base (3) and uridine-derived aldehyde (4) catalyzed by $\mathrm{Zn}(\mathrm{II})-(R, R)$-Linked-BINOL complex to give the desired stereoisomer selectively. The diazepinone ring system, another key structural element, was successfully constructed by vinyl halide-amide coupling promoted by $\mathrm{Cu}(\mathrm{I})$ salt. 
(Graphical Abstract)

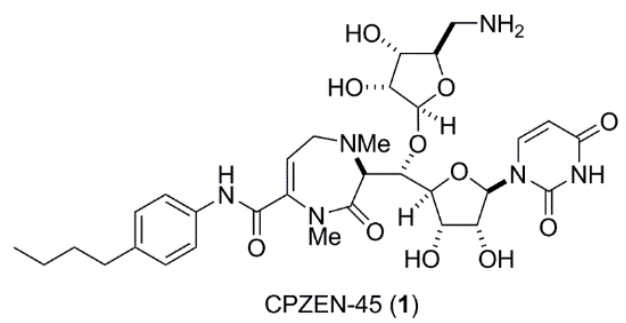

Keywords: CPZEN-45; Catalytic asymmetric aldol reaction; Anti-XDR-TB agent

* Corresponding authors, tel.: +81 33441 4173; fax: +81 334417589 (T.W.); tel.: +8133447 7779;

fax: $\quad+81334417589 \quad$ (M.S.); e-mail addresses: twatanabe@bikaken.or.jp (T.W.), mshibasa@bikaken.or.jp (M.S.). 


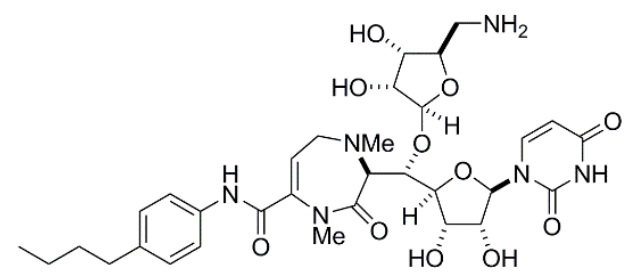

CPZEN-45 (1)

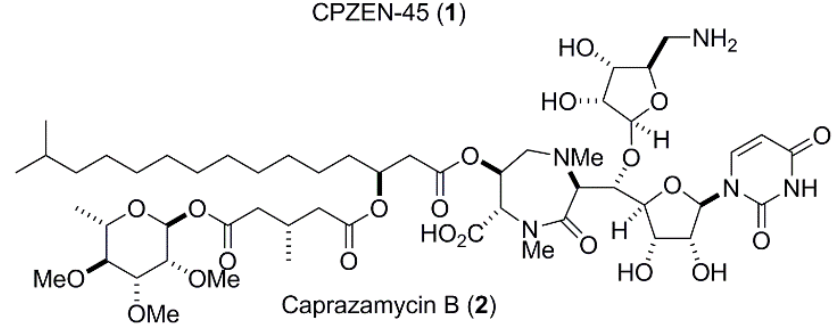

(Figure, no legend)

Tuberculosis (TB) has long been a serious threat to public health. In 2014, the World Health Organization reported 9.6 million new cases of TB worldwide and 1.5 million TB-related human deaths. ${ }^{1}$ Most alarming is that $3.3 \%$ of new cases and $20 \%$ of treated cases are multidrug-resistant TB (MDR-TB), 9.7\% of which are categorized as extensively drug-resistant TB (XDR-TB). XDR-TB is resistant to many clinically available anti-TB drugs, and has been reported in 105 counties to date. ${ }^{1}$ A promising tactic to combat the rapid spread of drug-resistance is the development of novel anti-TB agents with a mode of action distinct from that of the anti-TB drug precedents.

In 2003, caprazamycin B (2) was reported as a secondary metabolite of the actinomycete Streptomyces sp. MK730-62F2 that exhibits antibacterial activity against MDR-TB (minimum inhibitory concentration [MIC]: $3.13 \mu \mathrm{g} / \mathrm{mL}$ for Mycobacterium tuberculosis (M. tuberculosis) $\mathrm{H} 37 \mathrm{Rv}$ ) as well as against drug-sensitive strains (DS-TB, MIC ranging from $6.25-12.5 \mu \mathrm{g} / \mathrm{mL}$ ). ${ }^{2}$ 
The low water-solubility of $\mathbf{2}$, however, prevented the use of caprazamycin (a mixture of caprazamycin B and related compounds with varying side-chain substructures)for further preclinical studies, and led to structure-activity relationship (SAR) studies guided by the anti-TB activity and water miscibility. In 2013, Takahashi and co-workers disclosed the preparation and anti-TB activity of CPZENs, ${ }^{3}$ which were semi-synthetically derived from natural samples of caprazamycins. Among them, CPZEN-45 (1) displayed better anti-TB activity toward both MDR-TB (H37Rv; MIC: 1.56 $\mu \mathrm{g} / \mathrm{mL}$ ) and clinically isolated DS-TB strains (MIC: 0.78 to $12.5 \mu \mathrm{g} / \mathrm{mL}$ ) compared with caprazamycin B, with improved water-solubility and negligible acute toxicity. Notably, CPZEN-45 exhibited outstanding therapeutic efficacy in a murine TB model infected with an XDR-TB. Extensive biological studies revealed that the anti-TB activity stems from the inhibition of WecA, ${ }^{4}$ a key enzyme in the biosynthesis of mycolyl arabinogalactan, which is essential for the viability of Mycobacterium tuberculosis and yet has never been a molecular target of clinical anti-TB drugs. Due to its unique anti-TB profile and favorable physicochemical properties, CPZEN-45 is currently in the pipeline for anti-TB drug development at the stage of preclinical study (as of April 2016). ${ }^{5}$

The success of CPZEN-45 validated WecA as a convincing molecular target for exploratory studies of anti-TB medicines; thus, additional SAR studies using CPZEN-45 should be a reasonable strategy for obtaining anti-XDR-TB agents with more potent biological activity allowing for per os administration. Semi-synthetic SAR studies are effective when ample starting material of natural origin is available, but a major drawback of this strategy is the limited diversity of accessible 
compounds. For CPZEN-45, removal of the aminoribose moiety without damaging the rest of the structure, and skeletal alteration of the diazepinone core have not been achieved, and selective deletion or transformation of one particular functionality is nontrivial. Therefore, we planned a total synthesis of CPZEN-45 to expand the repertoire of available derivatives. Very recently, Takemoto and co-workers reported the first total synthesis of CPZEN-45. ${ }^{6}$

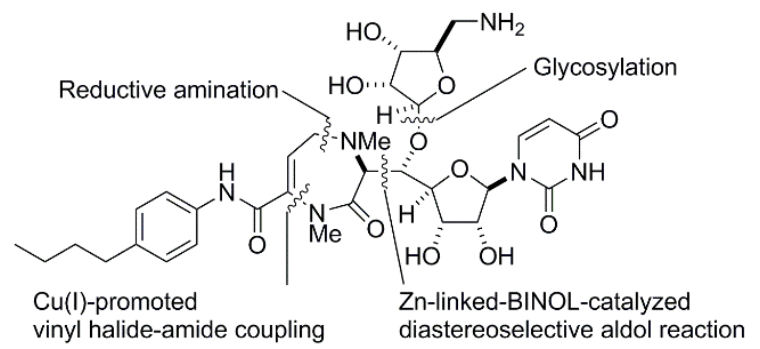

Figure 1. Synthetic strategy of CPZEN-45 (1).

We previously reported the catalytic asymmetric total synthesis of caprazol, ${ }^{7,8}$ a caprazamycin-related natural product lacking its side-chain moiety, and the synthesis of caprazamycin B (2). ${ }^{9,10}$ In the syntheses, catalytic asymmetric reactions developed in this laboratory $^{11}$ were successfully applied to furnish key stereochemical elements, such as a $\beta$-hydroxy- $\alpha$-amino acid structure within the diazepanone ring system, a $\beta$-hydroxyester of the side-chain portion, and an asymmetrically esterified 3-glutaric acid. As part of our ongoing synthetic studies of caprazamycin-related compounds, our synthetic strategy of CPZEN-45 is summarized in Figure 1. The $\beta$-hydroxy- $\alpha$-amino acid structure at the juncture between the uridine and diazepinone parts can be constructed by an aldol reaction of a glycine Schiff base with uridine-derived aldehyde, 
taking advantage of a catalyst system developed by our laboratory, a 2:1 complex of $\mathrm{Zn}(\mathrm{II})$ metal and $(R, R)$-linked-BINOL (5). ${ }^{12}$ These conditions considerably improved the diastereoselectivity of the syn-amino alcohol (7) from the isocyanoacetate-aldol reaction adopted in the total synthesis of caprazol $(\mathrm{dr}=\mathrm{ca} .4 / 1)$. The diazepinone ring system, another characteristic substructure of CPZEN-45, should be constructed by $\mathrm{Cu}(\mathrm{I})$-mediated vinyl halide-amide coupling, ${ }^{13}$ followed by glycosylation and amide formation.

Table 1 Optimization of aldol reaction catalyzed by $\mathrm{Zn}(\mathrm{II})-(R, R)$-Linked-BINOL.

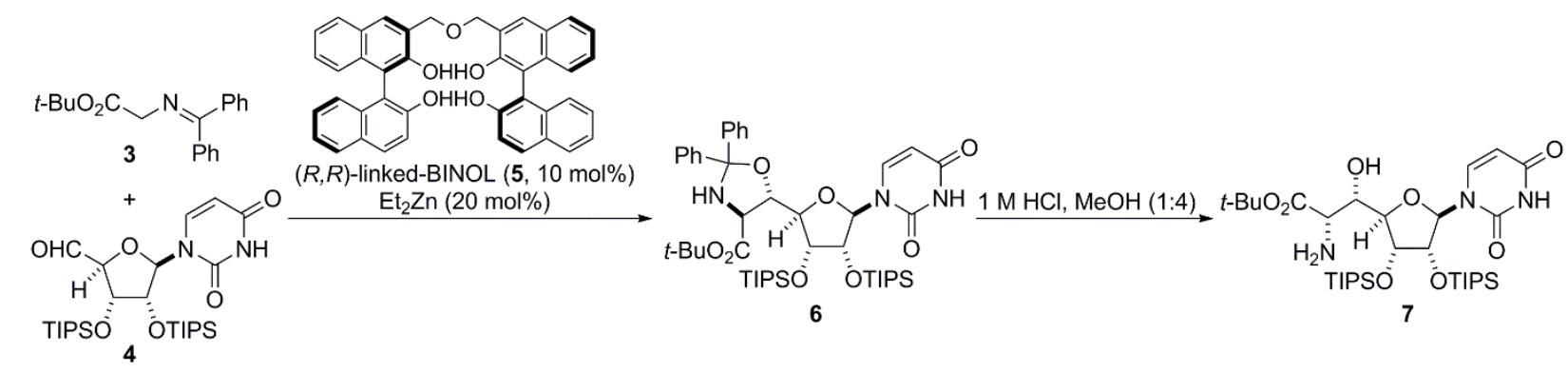

\begin{tabular}{|l|l|l|l|l|l|l|}
\hline entry & solvent & temp. & time (d) & yield of $\mathbf{6}$ & syn/anti of & $\mathrm{dr}$ of \\
\hline 1 & toluene & $\mathrm{rt}$ & 3 & 37 & $1.28 / 1$ & $6.4 / 1$ \\
\hline 2 & THF & $\mathrm{rt}$ & 14 & 85 & $9.3 / 1$ & $79 / 1$ \\
\hline 3 & THF & $40{ }^{\circ} \mathrm{C}$ & 3 & 60 & $4.4 / 1$ & $30 / 1$ \\
\hline $4^{\mathrm{a}}$ & THF & $40{ }^{\circ} \mathrm{C}$ & 3 & 57 & $3.35 / 1$ & $11.4 / 1$ \\
\hline 5 & $1,4-$ dioxane & $40{ }^{\circ} \mathrm{C}$ & 3 & 69 & $4.6 / 1$ & $13.8 / 1$ \\
\hline
\end{tabular}




\begin{tabular}{|l|l|l|l|l|l|l|}
\hline 6 & $\mathrm{DME}$ & $40{ }^{\circ} \mathrm{C}$ & 3 & 60 & $3.0 / 1$ & $6.67 / 1$ \\
\hline 7 & $\mathrm{Et}_{2} \mathrm{O}$ & $\mathrm{rt}$ & 14 & 51 & $2.55 / 1$ & $3.4 / 1$ \\
\hline 8 & $\mathrm{CH}_{2} \mathrm{Cl}_{2}$ & $\mathrm{rt}$ & 3 & 27 & $1 / 1$ & $1 / 1$ \\
\hline
\end{tabular}

${ }^{\mathrm{a}} 0.4$ equiv of Hunig's base was added.

At the outset of the synthesis, we screened the aldol reaction conditions using glycine Schiff $\mathbf{3}$ and uridine-derived aldehyde $\mathbf{4}$ as substrates to give the oxazolidine product $\mathbf{6}$. The product was hydrolyzed to result in the corresponding amino alcohol 7 with which stereoselectivity could be determined by NMR. After the initial disappointing results when using $(R)$-LLB $(37 \%$, syn/anti $=$ $1.4 / 1, \mathrm{dr}$ of $s y n=3.9 / 1)^{14}$ and the $\mathrm{Zn}(\mathrm{II})-(R)-$ Schiff base catalyst $(42 \%$, syn/anti $=2.5 / 1$, dr of $\operatorname{syn}=$ $3.6 / 1),{ }^{15}$ we found that the diastereoselectivity $(6.4 / 1)$ of the syn-product was promising when using a catalyst system comprising $\mathrm{Et}_{2} \mathrm{Zn}(20 \mathrm{~mol} \%)$ and $(R, R)$-linked-BINOL ${ }^{12}(\mathbf{5}, 10 \mathrm{~mol} \%)$ in toluene at room temperature for 3 days (Table 1, entry 1). Even in this case, however, the chemical yield (37\%) and the syn/anti selectivity (1.28/1) were unsatisfactory. Changing the solvent to THF increased the syn/anti ratio to $9.3 / 1$, and the diastereoselectivity of the syn-product was increased up to $79 / 1$ (entry 2). Notably, a reaction time as long as 14 days was required for isomerization of cis-oxazolidine to the trans-isomer to attain excellent syn-selectivity of the amino alcohol 7. To shorten the reaction time, we tried to facilitate the isomerization with gentle warming up to $40{ }^{\circ} \mathrm{C}$ (entry 3 ) and the addition of an external base ( 0.4 equiv of Hünig's base, entry 4$)$, but failed to improve the reaction 
time. Other ethereal solvents, such as 1,4-dioxane, 1,2-dimethoxyethane (DME), and diethyl ether (entries 5-7), failed to give better results, and no selectivity was observed when using $\mathrm{CH}_{2} \mathrm{Cl}_{2}$ (entry 8), which rendered entry 2 as the best condition. This is the first example in which an iminoester was successfully used as a substrate for Zn-linked-BINOL-catalyzed asymmetric aldol reaction conditions.
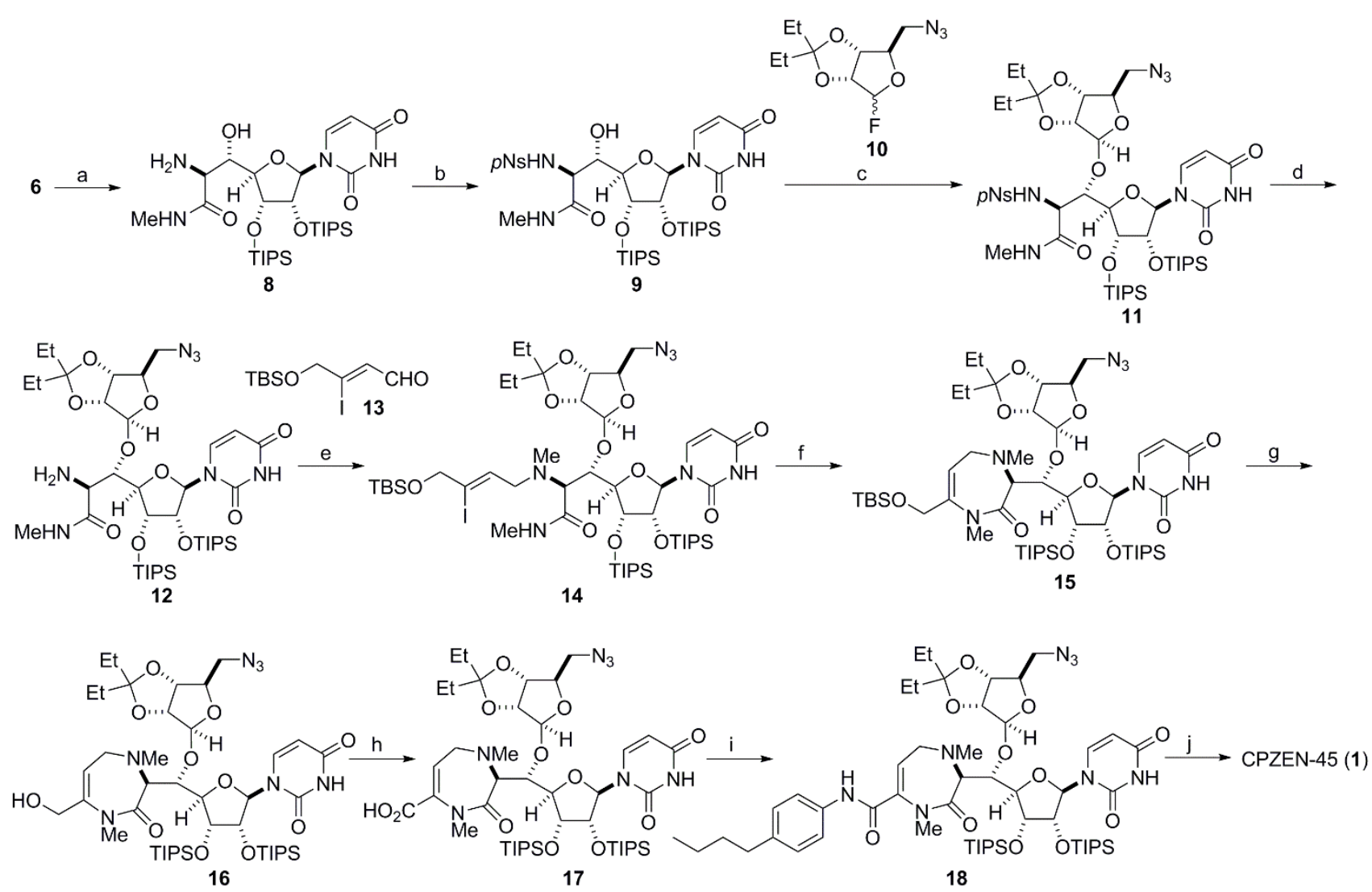

Scheme 1. Catalytic asymmetric synthesis of CPZEN-45 (1).

Reagents and conditions: (a) 1. TFA/Et ${ }_{3} \mathrm{SiH}(9: 1), \mathrm{rt}, 2.5 \mathrm{~h}$, then aqueous $\mathrm{MeOH}, \mathrm{rt}, 1 \mathrm{~h} ; 2 . \mathrm{MeNH}_{2}$, EDCI, $\mathrm{HOBt}, \mathrm{CH}_{2} \mathrm{Cl}_{2}$ rt, 14 h, 58\% (2 steps); (b) $p \mathrm{NsCl}, \mathrm{Et}_{3} \mathrm{~N}, \mathrm{CH}_{2} \mathrm{Cl}_{2}, 1 \mathrm{~h}, \mathrm{rt}, 72 \%$; (c) 10, $\mathrm{BF}_{3} \cdot \mathrm{OEt}_{2}, \mathrm{MS} 4 \mathrm{~A}, \mathrm{CH}_{2} \mathrm{Cl}_{2}, 40{ }^{\circ} \mathrm{C}, 15 \mathrm{~h}, 70 \%$; (d) $\mathrm{HSCH}_{2} \mathrm{CO}_{2} \mathrm{H}, \mathrm{K}_{2} \mathrm{CO}_{3}, \mathrm{MeOH}, \mathrm{rt}, 24 \mathrm{~h}, 74 \%$; (e) 13, $\mathrm{AcOH}, \mathrm{NaBH}_{3} \mathrm{CN}, \mathrm{AcOEt}, \mathrm{rt}, 15 \mathrm{~min}$; then $\mathrm{HCHO}$ aq, rt, 1 h, 92\% (2 steps); (f) CuI, DMEDA, 
$\mathrm{Cs}_{2} \mathrm{CO}_{3}, 1,4$-dioxane, $120{ }^{\circ} \mathrm{C}, 8 \mathrm{~h}, 72 \%$; (g) $3 \mathrm{HF} \cdot \mathrm{Et}_{3} \mathrm{~N}, \mathrm{Et}_{3} \mathrm{~N}, \mathrm{CH}_{3} \mathrm{CN}, \mathrm{rt}, 8 \mathrm{~h}, 86 \%$; (h) 1. DMP, $\mathrm{CH}_{2} \mathrm{Cl}_{2}, \mathrm{rt}, 25$,mim; 2. $\mathrm{NaClO}_{2}, 2$-methyl-2-butene, THF, then $\mathrm{NaH}_{2} \mathrm{PO}_{4}$ aq, rt, 20 min; 3. 4-n-butylaniline, COMU, Et $3 \mathrm{~N}, \mathrm{DMF}, \mathrm{rt}, 5.5 \mathrm{~h}, 81 \%$ (3 steps); (i) $3 \mathrm{HF} \cdot \mathrm{Et}_{3} \mathrm{~N}, \mathrm{Et}_{3} \mathrm{~N}, \mathrm{CH}_{3} \mathrm{CN}, 60{ }^{\circ} \mathrm{C}$, 12 h, 97\%; (j) 1. Zn, $n$-BuOH, $\mathrm{NH}_{4} \mathrm{Cl}$ aq, rt, 2 h; $2.80 \%$ TFA, rt, 1 h, then purification by HPLC and Dowex ${ }^{\circledR} 66$ free base, $64 \%$ (2 steps).

For total synthesis, the oxazolidine intermediate 6 was treated with a mixture of TFA and $\mathrm{Et}_{3} \mathrm{SiH}(9: 1)$ followed by the addition of aqueous $\mathrm{MeOH}$ to give the $\beta$-hydroxy- $\alpha$-amino acid, which was transformed into amide $\mathbf{8}$ by coupling with methylamine in $61 \%$ yield over 2 steps. After protection of the primary amine by a $p \mathrm{Ns}$ group $(\mathbf{9}, 63 \%$ yield $),{ }^{16} \mathrm{BF}_{3} \cdot \mathrm{OEt}_{2}$-promoted glycosylation ${ }^{8 b, 17}$ with the fluororibose derivative $\mathbf{1 0}$ according to the protocol reported by Matsuda and Ichikawa effectively furnished the corresponding glycoside $\mathbf{1 1}$ in $70 \%$ yield. Next, removal of the $p \mathrm{Ns}$ group gave rise to $\mathbf{1 2}$ in $74 \%$ yield, which was followed by introduction of the iodoolefin substructure in sequential one-pot reductive amination reactions using $\mathrm{NaBH}_{3} \mathrm{CN}$ as a reductant. The first step with $\mathbf{1 2}$ and crotyl aldehyde derivative $\mathbf{1 3},{ }^{18}$ and the second step with formalin resulted in the uneventful production of diazepinone precursor 14 (92\% yield). Next, we examined the second key transformation, $\mathrm{Cu}(\mathrm{I})$-mediated vinyl halide-amide coupling ${ }^{13 \mathrm{a}}$; cyclization proceeded smoothly by heating a mixture of $\mathbf{1 4}, \mathrm{CuI}$ (1 equiv), DMEDA (2 equiv), and $\mathrm{Cs}_{2} \mathrm{CO}_{3}$ (2 equiv) in 1,4-dioxane under reflux at $120{ }^{\circ} \mathrm{C}$ to construct the enamide structure (15) with a reasonable yield of $72 \%$. An 
alternative approach in which the anilide portion was installed prior to the cyclization was not successful due to the unavoidable $\beta$-elimination at the iodoolefin functionality under the basic conditions. $^{19}$

The endgame of the total synthesis was initiated with deprotection to unveil the primary hydroxyl group $(\mathbf{1 6}, 86 \%)$. Carboxylic acid 17 was obtained by the standard two-step oxidation procedure, and subsequent condensation with 4-n-butylaniline using COMU as the coupling reagent afforded 18 with the whole carbon framework of CPZEN-45 in its structure (81\% over 3 steps). ${ }^{20}$ After removal of the TIPS groups by $3 \mathrm{HF} \cdot \mathrm{Et}_{3} \mathrm{~N}$ (97\% yield), the azide group was reduced under Zn-mediated conditions. Eventually, hydrolysis of the acetal with wet TFA gave CPZEN-45 in a form of TFA salt, which was purified by HPLC to give CPZEN-45 2TFA salt. The resulting CPZEN-45 2TFA salt was treated with ion-exchange resin, Dowex ${ }^{\circledR} 66$ free base, to complete total synthesis of CPZEN-45 TFA salt. All of the physicochemical data, including ${ }^{1} \mathrm{H}$ and ${ }^{13} \mathrm{C}$ NMR of the synthetic material, were fully identical to that obtained from the natural sample. ${ }^{3}$

In conclusion, a catalytic asymmetric total synthesis of CPZEN-45 (1), an anti-XDR-TB gent, was accomplished using an aldol reaction of a glycine Schiff base and a uridine-derived aldehyde catalyzed by the $\mathrm{Zn}(\mathrm{II})-(R, R)$-linked-BINOL complex to give the desired stereoisomer selectively. The diazepinone part, another key structural element, was successfully constructed by vinyl halide-amide coupling promoted by $\mathrm{Cu}(\mathrm{I})$ salt. Further SAR studies of CPZEN-45-related compounds to search for anti-TB agents with more potent activity through this synthetic route are 
currently underway.

\section{Acknowledgments}

M.S. is grateful to the JST, and ACT-C and T.W. gratefully acknowledges the Takeda Science Foundation and KAKENHI (No. 26460168). The authors are thankful to Dr. Ryuichi Sawa, Ms. Yumiko Kubota, Ms. Kiyoko Iijima, and Ms. Yuko Takahashi (BIKAKEN) for spectroscopic analysis; and to Dr. Yoshiaki Takahashi (BIKAKEN) for providing an authentic sample of CPZEN-45 $\mathrm{HCl}$ salt. The authors appreciate valuable suggestion from Dr. Kazushige Sasaki and Dr. Hisashi Takada upon preparation of CPZEN-45 TFA salt, instructions for HPLC purification of CPZEN-45 by Dr. Masayuki Igarashi and Ms. Maya Umekita, and technical help by Ms. Chiharu Sakashita (BIKAKEN).

\section{References and notes}

1. Global Tuberculosis Report 2015; WHO Ed.; WHO Press; Geneva, 2015.

2. (a) Igarashi, M.; Nakagawa, N.; Doi, N.; Hattori, S.; Naganawa, H.; Hamada, M. J. Antibiot. 2003, 56, 580. (b) Igarashi, M.; Takahashi, Y.; Shitara, T.; Nakamura, H.; Naganawa, H.; Miyake, 
T.; Akamatsu, Y. J. Antibiot. 2005, 58, 327.

3. Takahashi, Y.; Igarashi, M.; Miyake, T.; Soutome, H.; Ishikawa, K.; Komatsuki, Y.; Koyama, Y.; Nakagawa, N.; Hattori, S.; Inoue, K.; Doi, N.; Akamatsu, Y. J. Antibiot. 2013, 66, 171.

4. Ishizaki, Y.; Hayashi, C.; Inoue, K.; Igarashi, M.; Takahashi, Y.; Pujari, V.; Crick, D. C.; Brennan, P. J.; Nomoto, A. J. Biol. Chem. 2013, 288, 30309.

5. http://www.newtbdrugs.org/pipeline.php (by Working Group on New TB Drugs, Stop TB Partnership)

6. Nakamura, H.; Yoshida, T.; Tsukano, C.; Takemoto, Y. Org. Lett., in press, DOI: 10.1021/acs.orglett.6b00943.

7. Gopinath, P., Wang, L., Abe, H., Ravi, G., Masuda, T., Watanabe, T., Shibasaki, M. Org. Lett., 2014, 16, 3364.

8. For the pioneering total synthesis of caprazol, see: (a) Hirano, S.; Ichikawa, S.; Matsuda, A. Angew. Chem. Int. Ed. 2005, 44, 1854. (b) Hirano, S.; Ichikawa, S.; Matsuda, A. J. Org. Chem. 2007, 72, 9936.

9. (a) Abe, H.; Gopinath, P.; Ravi, G.; Wang, L.; Watanabe, T.; Shibasaki, M. Tetrahedron Lett. 2015, 56, 3782. (b) Gopinath, P.; Watanabe, T.; Shibasaki, M. J. Org. Chem. 2012, 77, 9260.

10. For the pioneering total synthesis of caprazamycin A, see: Nakamura, H.; Tsukano, C.; Yasui, M.; Yokouchi, S.; Igarashi, M.; Takemoto, Y. Angew. Chem. Int. Ed. 2015, 54, 3136.

11. (a) Nitabaru, T.; Kumagai, N.; Shibasaki, M. Tetrahedron Lett. 2008, 49, 272. (b) Nitabaru, T.; 
Nojiri, A.; Kobayashi, M.; Kumagai, N.; Shibasaki, M. J. Am. Chem. Soc. 2009, 131, 13860. (c)

Nitabaru, T.; Kumagai, N.; Shibasaki, M. Angew. Chem. Int. Ed. 2012, 51, 1644. (d) Kawato, Y.;

Iwata, M.; Yazaki, R.; Kumagai, N.; Shibasaki, M. Tetrahedron 2011, 67, 6539. (e) Kawato, Y.;

Sandeep, C.; Kumagai, N.; Shibasaki, M. Chem. Eur. J. 2014, 19, 3802. (f) Gopinath, P.;

Watanabe, T.; Shibasaki, M. Org. Lett. 2012, 14, 1358. (g) Matsunaga, S.; Shibasaki, M. Synthesis 2013, 45, 421.

12. (a) Yoshikawa, N.; Kumagai, N.; Matsunaga, S.; Moll, G.; Ohshima, T.; Suzuki, T.; Shibasaki, M. J. Am. Chem. Soc. 2001, 123, 2466. (b) Kumagai, N.; Matsunaga, S.; Kinoshita, T.; Harada, S.; Okada, S.; Sakamoto, S.; Yamaguchi, K.; Shibasaki, M. J. Am. Chem. Soc. 2003, 125, 2169. (c) Shibasaki, M.; Matsunaga, S. Chem. Soc. Rev. 2006, 35, 269.

13. (a) Hu, T.; Li, C. Org. Lett., 2005, 7, 2035. (b) Jiang, L.; Job, G. E.; Klapars, A. Buchwald, S. L. Org. Lett., 2003, 5, 3667. For review, see: (c) Surry, D. S.; Buchwald, S. L. Chem. Sci. 2010, 1, 13. For related reactions, see: (d) Shen, R.; Porco, Jr. J. A. Org. Lett., 2000, 2, 1333.

14. Yoshikawa, N.; Yamada, Y. M. A.; Das, J.; Sasai, H.; Shibasaki, M. J. Am. Chem. Soc. 1999, 121, 4168. For the structure of LLB, see Figure S1.

15. Harada, S.; Gnanadesikan, V.; Matsunaga, S.; Shibasaki, M. J. Am. Chem. Soc. 2007, 129, 4900. For the structure of "Schiff base", see Figure S1.

16. Kan, T.; Fukuyama, T. Chem. Commun., 2004, 353.

17. Hirano, S.; Ichikawa, S.; Matsuda, A. J. Org. Chem. 2008, 73, 569. 
18. Li, H.; Morin, C. Tetrahedron Lett. 2004, 45, 5673.

19.

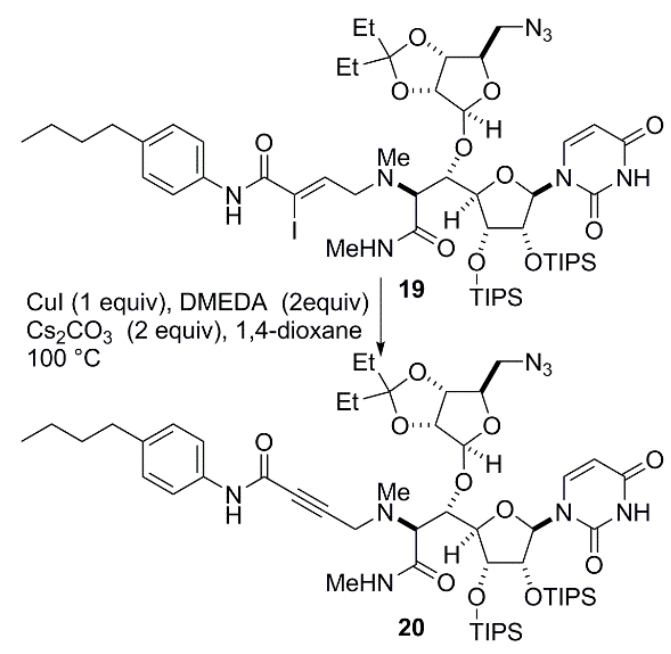

For example, the reaction using 19 bearing an anilide moiety suffered from facile $\beta$-elimination to give $\mathbf{2 0}$ exclusively.

20. El-Faham, A.; Funosas, R. S.; Prohens, R.; Albericio, F.; Chem. Eur. J., 2009, 15, 9404. 


\section{Legends of Artworks}

Figure 1. Synthetic strategy of CPZEN-45 (1).

Table 1 Optimization of aldol reaction catalyzed by $\mathrm{Zn}(\mathrm{II})-(R, R)-$ Linked-BINOL.

Scheme 1. Catalytic asymmetric synthesis of CPZEN-45 (1).

Reagents and conditions: (a) 1. TFA/Et ${ }_{3} \mathrm{SiH}(9: 1), \mathrm{rt}, 2.5 \mathrm{~h}$, then aqueous $\mathrm{MeOH}, \mathrm{rt}, 1 \mathrm{~h} ; 2 . \mathrm{MeNH}_{2}$, EDCI, $\mathrm{HOBt}, \mathrm{CH}_{2} \mathrm{Cl}_{2} \mathrm{rt}, 14 \mathrm{~h}, 58 \%$ (2 steps); (b) $p \mathrm{NsCl}, \mathrm{Et}_{3} \mathrm{~N}, \mathrm{CH}_{2} \mathrm{Cl}_{2}, 1 \mathrm{~h}, \mathrm{rt}, 72 \%$; (c) 10, $\mathrm{BF}_{3} \cdot \mathrm{OEt}_{2}, \mathrm{MS} 4 \mathrm{~A}, \mathrm{CH}_{2} \mathrm{Cl}_{2}, 40{ }^{\circ} \mathrm{C}, 15 \mathrm{~h}, 70 \%$; (d) $\mathrm{HSCH}_{2} \mathrm{CO}_{2} \mathrm{H}, \mathrm{K}_{2} \mathrm{CO}_{3}, \mathrm{MeOH}, \mathrm{rt}, 24 \mathrm{~h}, 74 \%$; (e) 13, $\mathrm{AcOH}, \mathrm{NaBH}_{3} \mathrm{CN}, \mathrm{AcOEt}, \mathrm{rt}, 15$ min; then $\mathrm{HCHO}$ aq, rt, 1 h, 92\% (2 steps); (f) CuI, DMEDA, $\mathrm{Cs}_{2} \mathrm{CO}_{3}, 1,4$-dioxane, $120{ }^{\circ} \mathrm{C}, 8 \mathrm{~h}, 72 \%$; (g) $3 \mathrm{HF} \cdot \mathrm{Et}_{3} \mathrm{~N}, \mathrm{Et}_{3} \mathrm{~N}, \mathrm{CH}_{3} \mathrm{CN}, \mathrm{rt}, 8 \mathrm{~h}, 86 \%$; (h) 1. DMP, $\mathrm{CH}_{2} \mathrm{Cl}_{2}$, rt, 25 min; 2. $\mathrm{NaClO}_{2}, 2$-methyl-2-butene, THF, then $\mathrm{NaH}_{2} \mathrm{PO}_{4}$ aq, rt, 20 min; 3. 4-n-butylaniline, COMU, Et ${ }_{3} \mathrm{~N}, \mathrm{DMF}, \mathrm{rt}, 5.5 \mathrm{~h}, 81 \%$ (3 steps); (i) $3 \mathrm{HF}^{\mathrm{E}} \mathrm{Et}_{3} \mathrm{~N}, \mathrm{Et}_{3} \mathrm{~N}, \mathrm{CH}_{3} \mathrm{CN}, 60{ }^{\circ} \mathrm{C}$, $12 \mathrm{~h}, 97 \%$; (j) $1 . \mathrm{Zn}, n-\mathrm{BuOH}, \mathrm{NH}_{4} \mathrm{Cl}$ aq, rt, $2 \mathrm{~h} ; 2.80 \%$ TFA, rt, 1 h, then purification by HPLC and Dowex® 66 free base, 64\% (2 steps). 